\title{
Research on the Convergence of Tourism Industry and Cultural Industry in Shaanxi Province
}

\author{
Qihong Tan \\ Leisure Management School, Xi'an Eurasia University, Xi'an, Shaanxi, \\ 710065
}

\begin{abstract}
Cultural tourism has become a fashion, it leads people to enjoy the beautiful natural scenery, visit the precious historical and cultural treasures. It not only makes people get a rich and lively natural and cultural knowledge, but also to enable people to obtain a wealth of human knowledge. Because of the uniqueness of cultural tourism, it has become the most important development direction of the tourism industry in the 21st century. However, from the perspective of the world, China's research on the definition of cultural tourism and how to carry out cultural tourism development and other aspects of research, less development, lagging behind the rest of the world's developed countries. In China, there are some places do not pay much attention to the development of cultural tourism industry, or even do not know how to develop cultural tourism, or development level is very shallow, still remain in the initial stage of development. Although there are some places to realize the importance of protecting local characteristics and cultural tourism, there are still some problems in the development of culture tourism, such as the incorrect idea of development and the insufficient development of cultural tourism, and the potential advantage of cultural tourism is not fully brought into full play.
\end{abstract}

Keywords: Shaanxi, Tourism Industry, Culture Industry, Integration 


\section{Introduction}

At present, the upsurge of cultural tourism and the imbalance of supply and demand of cultural tourism have led to the lack of spiritual and cultural life and the low taste of leisure tourism. Therefore, the development of cultural tourism industry has not only become an important trend of domestic cultural industry and tourism industry development, Of the social value. In recent years, Shaanxi Province attaches great importance to the development of cultural tourism industry, even in the province, "Twelfth Five-Year Plan" proposed in the "second Five-Year" at the end of the province's GDP, the cultural industry added value of more than 5\%; The "second Five-Year" period, the growth rate of tourism is higher than the national average growth rate of tourism and higher than the province's GDP growth. Although the cultural tourism industry in Shaanxi Province has a good foundation and conditions for development, and in recent years has achieved relatively good results, showing a comprehensive, multi-level, wide area of integration of the development trend. But overall, the province of Shaanxi cultural tourism resources, industry, the basic pattern of small province has not fundamentally changed, and catch up with the neighboring provinces, there is still a big gap.

\section{Integration of tourism and cultural industries}

\subsection{The inherent mechanism of the integration of tourism industry and cultural industry}

The innovation of production technology is the fundamental motive for the development of industrial integration, and the integration of tourism industry and cultural industry is no exception. In the era of knowledge economy, the rapid development of information industry has played a crucial role in the innovation and rapid dissemination of knowledge. The development of information technology has a qualitative impact on the wide dissemination of culture and the transformation of cultural industry operating mode. The continuous diffusion of information, so that cultural exchanges continue to deepen and diversify, so more conducive to cultural innovation and recycling. At the same time, the development of information technology and the application of high-tech science and technology have also changed the traditional business model of the tourism industry, causing a huge crisis to the tourism industry, such as tourism ecommerce and online travel consulting business to the traditional travel agency industry Development has brought great challenges.

Tourism industry for the development of tourism resources used by the technology is the tourism industry's technical boundaries. Cultural industry will be a variety of cultural resources into the corresponding cultural products and services, production technology, constitute the technical boundaries of the cultural industry. For the cultural industry and the tourism industry, technology integration needs to be discussed from two aspects, this paper based on the 
development of tourism industry for the spiritual and cultural elements of the special needs will lead to cultural industries and tourism industry integration of technical factors are divided into: hard and soft technology One aspect. Any new culture, new ideas, new technologies, new lifestyles can stimulate the interest of tourists, so some cultural products are also derived as tourism resources. The above mentioned new culture, new ideas, new ways of life for the integration of tourism and cultural industries in terms of belonging to the soft-technology category, as mentioned above, the same as the management of industrial integration motivation, is more spiritual culture. In the tourism industry and the integration of cultural industries called the concept of innovation is more appropriate. The "hard technology" that promotes the integration of the two is the application of the information industry and high-tech in the cultural industry and has the property of being universal to the tourism industry, or the application of high-tech in the tourism industry. The spread of culture and the development of cultural industry With asset versatility.

\subsection{Tourism industry and cultural industry integration external impetus}

Before the reform and opening up in China there is no tourism and cultural industries of the two terms, cultural and cultural title, tourism is mainly foreign affairs reception. Neither has significant economic significance. Culture as the dissemination of national thinking, carry forward the meaning of the traditional classical system is constrained by the shackles of all cultural production and consumption are planned and organized. With the reform and opening up, political and economic system of continuous reform, the market continued to open, and its cultural effects began to emerge. Relaxation of government regulation makes barriers to entry between the industry lower, expanding the scope of industrial production, thus the inter-industry penetration, cross and the integration of production possible, industrial structure tends to optimize. At the same time, the relaxation of regulation is conducive to the diversification of the industry. In particular, the cultural industry has a broader space for the creation of cultural contents, which is conducive to the development and promotion of the cultural essence of our country. This is from the United States for the laissez-faire policy of the cultural industry, the results can be seen in general.

\section{Tourism industry and cultural industry integration development model}

Cultural consumption is an important content of tourism consumption, tourism activities is a flow of cultural activities; culture can reflect and sublimation of nature, culture, natural vitality and aura. Therefore, the integration of tourism industry and cultural industry development, for the promotion of value-added tourism products and cultural industries to convey the cultural connotation of publicity play a multiplier role. This fully proves that industrial integration is the only way to optimize the upgrading of industrial structure. Functional sub- 
integration model is the two industrial activities can be parallel and co-create benefits for this type of tourism industry integration model is not taken. Because the integration of technology is the criterion of industrial convergence, such sports tourism, medical tourism, incentive tourism can be called a new model of tourism development at best, which is a new form of tourism market expansion. Because this is a parallel between the two activities, there is no technology between the industry, business cross.

Resource sharing tourism industry integration model refers to the different industries, mainly referring to one or two industry resources can also be used as tourism resources re-asset reorganization, transformation, for tourism development or tourism integration development. Eco-tourism and cultural and creative tourism are all part of this tourism integration development model. The reason why the industrial tourism for cultural and creative tourism, because the British industrial development period will be a large number of waste factory area for the transformation of cultural and creative industries park to promote the development of cultural and creative industries at the same time attracting many tourists come to visit. Since then, countries around the world have followed, such as Beijing's 798 cultural and creative area is the use of this industry integration development model, which is the core area of regional cultural and creative industries have become an important tourist attraction.

As discussed above, the research on the development pattern of tourism industry integration can be classified from the perspective of the versatility of assets. The products with the versatility of assets are substituted, supplemented and regrouped in the process of being used for other industries, so as to explain the difference between the commonality of assets and the cost of asset conversion in the process of integration between industry and industry. Level, the same there are three types of industrial development model.

\section{Suggestions on Promoting the Development of Cultural Tourism Industry in Shaanxi Province}

We should deepen the reform of the administrative system, speed up the transformation of government functions, and promote the separation of government functions and business management, cultural tourism industry to break the multi-sectoral regulation. Narrow the scope of government commitment to things, and strictly limit the government departments of cultural tourism enterprises and market intermediaries in the direct intervention. To solve the government departments of cultural tourism enterprises in the economic investment, personnel arrangements for the direct intervention, to further promote the separation of government and assets, breaking the bond between the government and enterprises. Innovation management mechanism, and further the cultural resource management as a whole, each management should actively cooperate closely with the formation of complementary management functions, to avoid excessive management and loss of management of the phenomenon. 
Shaanxi Province should make full use of the advantages of rich cultural tourism resources, dig deep into its culture, can use cultural resources to attract the technology, capital and market access to it, and can also implement some preferential policies for international and domestic cultural tourism enterprises To the development of Shaanxi to provide "green channel" to reduce the complexity of the procedures for the reduction of a certain percentage of tax concessions, improve the investment policy, innovative investment approach. Only large-scale cultural tourism enterprises at home and abroad to participate in the cultural tourism industry in Shaanxi Province to the development of this family to the cultural tourism in Shaanxi Province for the development and expansion to contribute.

Hotel, transportation, tourism souvenirs as the tourism industry in Shaanxi Province cluster elements, is still in its infancy. So far, Shaanxi Province to receive high-end consumer and large-scale meeting of the star hotel is also a handful. Although the catering industry in Shaanxi Province has been a wellknown tourist resources, but has not yet formed a complete system, did not do the combination of industry and size. At the same time, entertainment facilities are not perfect, did not achieve the purpose of stimulating consumption. Tourismrelated product development is basically fragmented, which is very inconsistent with the cluster of the tourism industry, so the need for government guidance and support. On the other hand, the tourism industry cluster is an industry related to all walks of life, tourism industry and related industries is a complementary development of the relationship between the common development. While striving to develop the tourism industry, it is necessary to organically link all kinds of cluster elements, such as industry and commerce, so as to promote propaganda work at the same time, strive to create a cultural connotation, suitable for living and able to start a business.

\section{Conclusion}

The development of cultural tourism industry is the inevitable result of modern economic development. This paper analyzes the present situation of cultural tourism industry in Shaanxi Province and points out the problems in the development of cultural tourism industry in Shaanxi Province. The paper uses the gray correlation model to analyze the influence of cultural tourism industry on the basis of the basic meaning of cultural tourism industry. The paper puts forward the tentative plan of cultural tourism industry in Shaanxi Province and discusses the policy suggestion of cultural tourism industry development in Shaanxi Province from the macroscopic level. 


\section{References}

[1] Wang Hao, Luo Zongliang. Zhang Daqian poetry cultural tourism product development model [J]. Journal of Neijiang Teachers College, 01(8), pp. 12-15, 2014

[2] Ma Zhenqing, Fang Qiu.Study on the Development Strategy of Cultural Tourism Souvenirs of Crane in Qiqihar City [J]. China Management Informationization, 29(8), pp. 61-76, 2014

[3] He Ying. Reflections on the Development of Urban Cultural Tourism in Gansu [J]. Development, 6(2), pp. 54-56, 2011

[4] Zhao Xiaofeng. Inner Mongolia grassland cultural tourism development research [J]. China Management Informationization, 12(22), pp. 23-33, 2014

[5] Li Zhao, Xie Yuanlu. Meishan, Sichuan, the development of cultural tourism problems and countermeasures [J]. Western Economic Management Forum, 15(21), pp. 18-52, 2014 